\title{
SCIENTIFIC REPORTS

\section{Modeling Differential Effects of Maternal Dietary Patterns across Severity Levels of Preterm Birth Using a Partial Proportional Odds Model}

\begin{abstract}
Aweke A. Mitku $\mathbb{1}^{1,4^{*}}$, Temesgen Zewotir ${ }^{1}$, Delia North ${ }^{1}$, Prakash Jeena ${ }^{2}$ \& Rajen N. Naidoo ${ }^{3}$
Preterm birth is a common cause of death worldwide of children under the age of five years. This condition is linked with short and long term neonatal morbidity and mortality. Maternal nutrition during pregnancy has a profound effect on fetal growth and development and subsequently also on the incidence of preterm birth. The aim of this study was to assess the differential effect of dietary patterns of pregnant women across ordered levels of preterm birth. Dietary assessments were performed using a food frequency questionnaire, presented to 687 pregnant women, in the "Mother and Child in the Environment" birth cohort during the period of 2013 to 2017 . Each pregnancy resulted in a live birth. Eight dietary patterns were extracted, using exploratory factor analysis. The partial proportional odds model was employed to model severity levels of preterm birth. The partial proportional odds model has been recognized to be a flexible approach since it allows the effect of predictor variables to vary across categories of the ordinal response variable of interest. Women with increased consumption of vegetable-rich foods showed a reduced risk of very to moderately preterm birth incidence (AOR $=0.73$, $95 \% \mathrm{Cl}=(0.531,0.981), \mathrm{p}=0.036)$. Lower odds of very/moderately preterm birth compared to late preterm or term birth were observed for women following "nuts and rice foods" dietary pattern $(A O R=0.25,95 \% \mathrm{Cl}=(0.099,0.621), \mathrm{p}=0.003)$. High dietary consumption of starch foods dietary pattern ( $A O R=2.09,95 \% \mathrm{Cl}=(1.158,3.769), \mathrm{p}=0.014)$ was associated with the most severe level of preterm birth outcome incidence, i.e. very/moderately preterm birth. The partial proportional odds modeling allowed the description of the effect of maternal dietary patterns across the different severity levels of preterm birth.
\end{abstract}

The World Health Organization (WHO) has defined preterm birth as the spontaneous or induced live delivery of babies before 37 completed weeks of gestation ${ }^{1}$. Preterm birth is associated with short and long term neonatal morbidity and mortality ${ }^{2-5}$ and is the second-leading cause of under-five mortality, worldwide ${ }^{1}$. The global prevalence of preterm birth is $10 \%$, accounting for 15 million births, globally and approximately $50 \%$ of all perinatal deaths every year ${ }^{1,6}$. In South Africa, more than 8 out of 100 babies are preterm. The country was ranked $24^{\text {th }}$ out of 184 countries in 2010, for the number of newborn deaths, due to complications from preterm birth ${ }^{1}$.

With a few exceptions, the rate at which preterm birth occurs has grown in both developed and developing countries, over the last decade ${ }^{1,5}$. Increased maternal age during pregnancy, infertility treatment and maternal health conditions are the leading causes (1). However, changes in obstetric practice (evidenced by an increase in induced deliveries and cesarean section, are possible additional reasons for the increased incidence of preterm births ${ }^{1}$. The highest increase in preterm birth incidence was observed to be in the moderate preterm category (32-33 weeks' gestation), as well as the late preterm category (34-36 weeks' gestation $)^{7,8}$. Although considerable

${ }^{1}$ School of Mathematics, Statistics and Computer Science, College of Agriculture Engineering and Science, University of KwaZulu-Natal, Durban, South Africa. ${ }^{2}$ Discipline of Pediatrics and Child Health, School of Clinical Medicine, College of Health Sciences, University of KwaZulu-Natal, Durban, South Africa. ${ }^{3}$ Discipline of Occupational and Environmental Health, School of Nursing and Public Health, College of Health Sciences, University of KwaZulu-Natal, Durban, South Africa. ${ }^{4}$ Department of Statistics, Bahir Dar University, Bahir, Dar, Ethiopia. *email: mitkua@ukzn.ac.za 
attention has been paid to preterm birth as a whole, outcomes vary with the subcategories of preterm birth ${ }^{9-11}$. The rate of preterm birth has increased by $33 \%$ in the last 25 years, almost entirely due to the rise in late preterm births ${ }^{12}$. The extent of the increased risk of preterm birth associated with socio-economic disadvantage and other risk factors generally increased with an increasing severity level of preterm birth ${ }^{11}$.

Maternal nutrition has an effect on fetal growth ${ }^{13-16}$ and preterm deliveries ${ }^{17-21}$. Several studies have yielded varying results concerning the associations between single foods or nutrients during pregnancy and preterm birth incidence ${ }^{22-26}$. Other studies looking at dietary patterns of foods in combination during pregnancy have allowed for the interactive effect between nutrients and timing of deliveries to be studied ${ }^{27,28}$. As an example, a western diet, which is described as consisting of a high consumption of fried and processed meats, is associated with an increased risk of preterm birth ${ }^{24,29}$, while prudent diets, which are rich in vegetables and fruits, have been associated with a lower occurrence of preterm birth ${ }^{23}$.

The complexity of preterm birth suggests that a simple binary logistic regression approach fails to identify exposure effects at different severity levels of preterm birth ${ }^{24,29-31}$. Many researchers have applied newer statistical and scientific methods to identify the effect of dietary patterns on the incidence of preterm birth. Since it is not appropriate to assume that all the factors have the same effect across different severity levels of preterm birth, an ordinal logistic regression model was proposed for such investigation by Walker and Duncan ${ }^{32}$ and was later referred to as the proportional odds model ${ }^{33-36}$. The proportional odds model is a generalization of a binary logistic regression model, in which the response variable has more than two ordinal categories. The use of ordinal polytomous responses has increased significantly in health science studies on quality of life, defining health status indicators, the severity of certain diseases and the effectiveness of post-operative procedures ${ }^{36}$. Data in such studies are commonly evaluated by the proportional odds model ${ }^{33-35,37}$. The partial proportional odds model combines the ordered arrangement in ordinal models, while allowing for particular independent variables to affect different levels of the outcome variables ${ }^{28}$.

Even though maternal diet has been considered as a determinant of preterm birth prevalence in previous studies, the association with preterm birth is not well established in South Africa. South Africa is experiencing a transition in dietary patterns, from that of traditional diets to a more "Western" diet, high in fats and sugar ${ }^{38}$. It is, therefore, useful to assess the association of dietary patterns during pregnancy with preterm birth, in order to make informed decisions on dietary interventions during pregnancy ${ }^{27}$. We used a novel modeling strategy, the partial proportional odds model, which allows for more nuanced insights on the effect of dietary patterns across different severity levels of preterm birth than other approaches, such as the binary and multinomial logistic regression models. This paper attempts to model the differential effect of maternal dietary patterns, across the severity levels of preterm birth using the partial proportional odds model.

\section{Methods}

Data. The Mother and Child in the Environment (MACE) birth cohort is based among low-income communities in Durban, South Africa. The study enrolled 996 pregnant women between March 2013 and May 2017. Participants in the study were selected from public sector antenatal clinics in the industry dense residential areas in south Durban (Merebank, Bluff, Wentworth, and Austerville), as well as from residential located areas in the less heavily industrial areas in the north of Durban (Kwa Mashu, Newlands and Inanda). All pregnant women that met inclusion and exclusion criteria, were enrolled in the study and followed up during their pregnancy, through to labour and delivery. The inclusion criteria included gestational age less than 20 weeks and resident for the full duration of the pregnancy in the geographical area within which the clinic was located. Women with multiple pregnancies were excluded. Ethical approval was obtained from the University of KwaZulu-Natal's Biomedical Research Ethics Committee, and each participant provided informed consent, participation was voluntary and withdrawl from the study at any point was allowed.

Among the 996 enrolled pregnant women, 309 subjects were excluded due to miscarriages, termination of pregnancy and loss to follow up. The study analysed data on 687 pregnant women in the cohort. The food frequency questionnaire was administered to the mothers in the third trimester. Dietary patterns were based on the 75 food items commonly used in the maternal diet. According to $\mathrm{WHO}^{1}$ and Donoghue et al. ${ }^{39}$, preterm birth is classified as very preterm ( $<32$ weeks), moderately preterm (32-33 weeks), late preterm (34-37 weeks), and term (38-42 weeks).

Data reduction. To reduce the 75 dietary variables into a set of manageable latent characteristics, with minimal loss of information, exploratory factor analyses with a Promax rotation method was used. A scree plot (Fig. 1), along with the percentage of variance explained by each factor, was used to determine the number of latent factors. Accordingly, eight latent dietary factors that explain dietary patterns were identified. Collectively these factors explained $88.3 \%$ of the variability within the sample. These factors were labeled as 'energy foods and snacks', 'spreads and fast foods', 'butter, junk foods, and juices', 'protein-rich foods', 'starch foods', 'nuts and rice foods', 'vegetable-rich foods' and 'alcoholic drinks'. The summary of results, with the factor loadings and naming of the dietary patterns, is given in Table 1.

Data exploration. Exploration of the data was performed using parallel coordinate plots (PCP), in order to examine trends of dietary patterns across different severity levels of preterm birth. The PCP revealed an association between the higher-order severity levels 2 and 3 of preterm birth outcomes, with lower consumption of 'nuts and rice foods' dietary patterns (Fig. 2). Except for some outliers, similar PCP trends were observed for 'spreads and fast foods' dietary patterns. The PCP further displayed that the higher-order severity levels 2 and 3 of preterm birth, had a high range of variation from low to high on 'butter, junk foods, and juices' and 'energy foods and snacks' dietary patterns, with high clustering of late preterm birth at lower scores (Fig. 2). This supports the use 

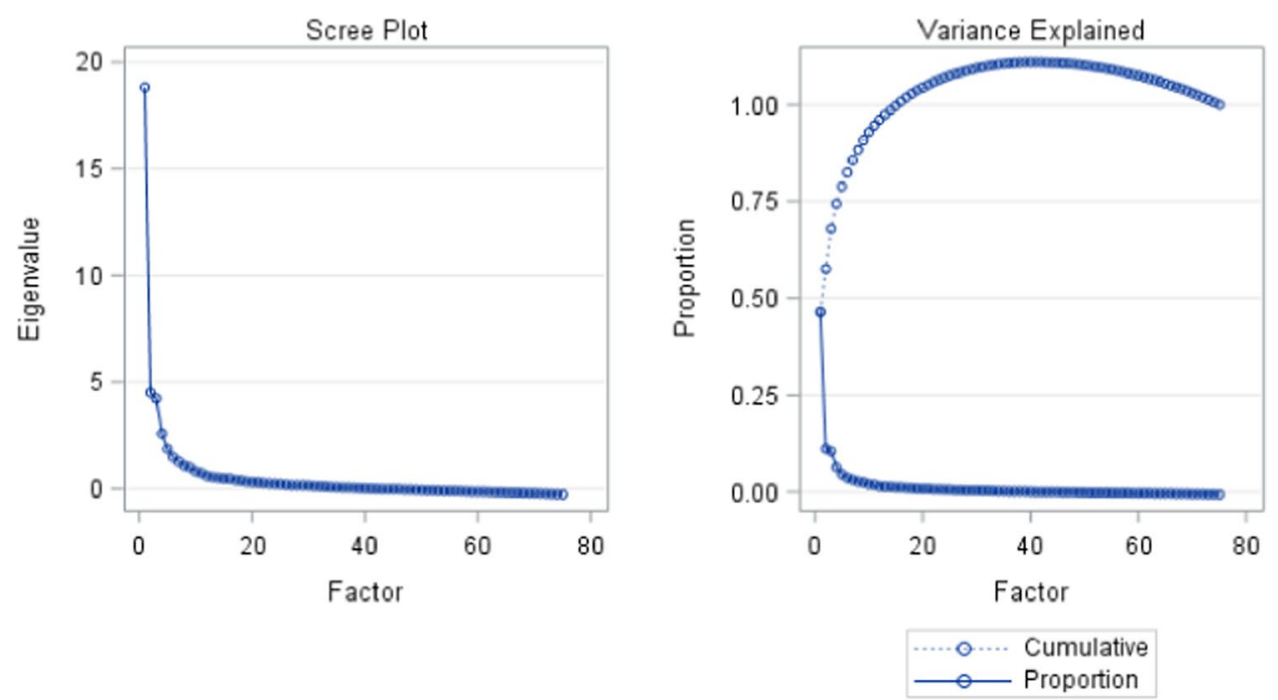

Figure 1. Scree plot and percentage of variance explained by factor analysis on maternal dietary patterns.

of a model (such as the partial proportional odds model) that considers the differential effect of dietary patterns across the severity levels of preterm birth.

Statistical analysis. Gestational age was categorized into three levels, based on the severity levels of preterm birth. The outcome variable of interest (severity level of preterm birth) was measured on three ordinal levels of term (38-42 weeks), late preterm (34-37 weeks) and very ( $<32$ weeks) or moderately preterm (32-33 weeks) birth. These sub-categories of preterm birth were coded to represent severity levels: term birth $=1$, late preterm birth $=2$, very or moderately preterm birth (most severe) $=3$. The level $\mathrm{k}=1$ defines the lowest severity level (term birth). Therefore, for the $i^{\text {th }}$ woman in the study, the response variable, the severity level of preterm birth $\left(Y_{i}\right), i=1 \ldots n$, is defined as follows

$$
Y_{i}=\left\{\begin{array}{l}
1: \text { if gestational age is between } 38 \text { and } 42 \text { weeks } \\
2: \text { if gestational age is between } 34 \text { and } 37 \text { weeks } \\
3: \text { if gestational age is between } 23 \text { and } 34 \text { weeks }
\end{array}\right.
$$

A proportional odds model is one in which the response variable has more than two ordinal categories, with the assumption of odds being the same across the categories. The partial proportional odds model is suitable in modeling severity levels of preterm birth due to the flexibility in the procedure, as it is capable of relaxing the proportional odds assumption in the ordered logit model, by allowing the variability of the regression parameter $\beta$, across severity levels of preterm birth, while maintaining its ordinal nature. It estimates the cumulative probabilities of being at or below, specific severity levels of preterm birth, given a set of independent variables ${ }^{33-35,40}$. The partial proportional odds model can be given as

$$
\operatorname{logit}\left[\frac{P\left(Y>j / x_{1} \ldots x_{p}\right)}{P\left(Y \leq j / x_{1} \ldots x_{p}\right)}\right]=\alpha_{j}+X_{i} \beta_{j} j=1,2, \ldots, k-1
$$

where $\mathrm{Y}$ is the ordinal response severity levels of preterm birth, $\mathbf{x}$ is the vector of observed explanatory variables: maternal and infant characteristics, including maternal dietary patterns, maternal age, maternal education, employment, maternal annual income, family size, gravida, and infant gender, $\boldsymbol{\beta}$ is the vector of estimable parameters and $\alpha$ is the unknown threshold, or intercept parameters. Consequently, the model in Eq. 1 is the partial proportional odds model.

The proportional odds, in particular, the probability of an observation being at, or above, a specific severity level of preterm birth, was conditional on maternal dietary practices and socio-demographic characteristics observed in the study. In fitting a partial proportional odds model, it is imperative to verify the homogeneity of the proportional odds ratios across all ordinal levels, using a global test of non-proportionality ${ }^{41}$. The predictors that met the proportional odds assumption, dietary patterns ('energy foods and snacks', 'spreads and fast foods', 'butter, junk foods, and juices', 'protein-rich foods', 'vegetable-rich foods and alcoholic drinks') and covariates (maternal employment, maternal age, maternal education and infant gender), have the same coefficient values in two of the cumulative logits, the higher severity levels (levels 2 or 3) versus the lowest level (level 1) and the most severe level (level 3) versus the lower severity levels (levels 1 or 2). We considered p-values below 0.05 to be statistically significant. SAS 9.4 was used for the analysis of the data.

Ethics approval and consent to participate. Written, informed consent was obtained from the mother for the children and provided their own consent. The study was approved by the Biomedical Research Ethics Committee of the University of KwaZulu-Natal. 


\begin{tabular}{|c|c|c|c|}
\hline Dietary patterns & Food items & $\begin{array}{l}\text { Factor loadings } \\
\text { coefficient* }\end{array}$ & $\begin{array}{l}\text { Cumulative variance } \\
\text { explained (\%) }\end{array}$ \\
\hline \multirow{23}{*}{ "Energy foods and snacks" } & Energy bars & 0.87486 & \multirow{23}{*}{$46.41 \%$} \\
\hline & Energy drinks & 0.85251 & \\
\hline & Ice cream & 0.76687 & \\
\hline & Chocolate & 0.74735 & \\
\hline & Drinking yogurt & 0.70387 & \\
\hline & Milk drinks & 0.70378 & \\
\hline & Milkshake & 0.66289 & \\
\hline & Fruit salad & 0.63208 & \\
\hline & Cheese sauce & 0.62704 & \\
\hline & Cheese & 0.56129 & \\
\hline & Chicken with skin & 0.47309 & \\
\hline & Chips & 0.46882 & \\
\hline & Cold meat & 0.46529 & \\
\hline & Red meat & 0.43206 & \\
\hline & $\begin{array}{l}\text { Flame-grilled fast-food } \\
\text { chicken }\end{array}$ & 0.42456 & \\
\hline & Hot dogs & 0.40035 & \\
\hline & \begin{tabular}{|l|} 
Sausages \\
\end{tabular} & 0.39612 & \\
\hline & Fizzy soft drinks & 0.38538 & \\
\hline & Fruit juice & 0.35977 & \\
\hline & Hamburgers & 0.31074 & \\
\hline & Pizza & 0.30266 & \\
\hline & Rusks & 0.30247 & \\
\hline & Cooking oil & -0.33744 & \\
\hline \multirow{25}{*}{ "Spreads and fast foods" } & Dripping & 0.76641 & \multirow{25}{*}{$11.12 \%$} \\
\hline & Salad dressing low fat & 0.76498 & \\
\hline & Fat Holsum & 0.74403 & \\
\hline & Schnitzels & 0.70762 & \\
\hline & Skimmed & 0.6791 & \\
\hline & \begin{tabular}{|l|} 
Chocolate spread \\
\end{tabular} & 0.60188 & \\
\hline & Bunny chow & 0.58556 & \\
\hline & Venison & 0.55576 & \\
\hline & Fizzy diet soft drinks & 0.51667 & \\
\hline & Fish steamed & 0.50548 & \\
\hline & Whole wheat & 0.49309 & \\
\hline & Dried fruit & 0.47822 & \\
\hline & Red meat fat removed & 0.47779 & \\
\hline & Cookies & 0.45296 & \\
\hline & Fried fast food chicken & 0.4281 & \\
\hline & Pasta & 0.42541 & \\
\hline & Organ meat & 0.40937 & \\
\hline & Nuts and peanuts & 0.36348 & \\
\hline & Pizza & 0.34863 & \\
\hline & Pies and sausage rolls & 0.34244 & \\
\hline & Vetkoek & 0.33541 & \\
\hline & Rusks & 0.32428 & \\
\hline & Hot dogs & 0.31508 & \\
\hline & Butter & 0.3194 & \\
\hline & Fizzy soft drinks & -0.31292 & \\
\hline \multirow{7}{*}{$\begin{array}{l}\text { "Butter, junk foods and } \\
\text { juices" }\end{array}$} & Butter & 0.623 & \multirow{7}{*}{$10.45 \%$} \\
\hline & \begin{tabular}{|l|} 
Sweets \\
\end{tabular} & 0.60625 & \\
\hline & Muffins & 0.59219 & \\
\hline & \begin{tabular}{|l|} 
Chips \\
\end{tabular} & 0.56772 & \\
\hline & Mixed salad & 0.56106 & \\
\hline & Fruit juice & 0.5389 & \\
\hline & Fresh fruit & 0.53471 & \\
\hline Continued & & & \\
\hline
\end{tabular}




\begin{tabular}{|c|c|c|c|}
\hline Dietary patterns & Food items & $\begin{array}{l}\text { Factor loadings } \\
\text { coefficient* }\end{array}$ & $\begin{array}{l}\text { Cumulative variance } \\
\text { explained (\%) }\end{array}$ \\
\hline & Fizzy soft drinks & 0.42281 & \\
\hline & Vetkoek & 0.39649 & \\
\hline & Coffee creamer & 0.38703 & \\
\hline & Cooking oil & 0.38482 & \\
\hline & Hamburgers & 0.36097 & \\
\hline & Cooked vegetables & 0.35781 & \\
\hline & Cereals Rice Crispies & 0.31854 & \\
\hline & Soft margarine & -0.77394 & \\
\hline \multirow{9}{*}{ "Protein-rich foods" } & Fried fish & 0.67237 & \multirow{9}{*}{$6.35 \%$} \\
\hline & Fish tinned & 0.54825 & \\
\hline & Fried fish in fat & 0.52289 & \\
\hline & Eggs cooked or poached & 0.46767 & \\
\hline & White brown bread & 0.43925 & \\
\hline & Potato chips & 0.4079 & \\
\hline & Chicken with skin & 0.40252 & \\
\hline & Chicken without skin & -0.34525 & \\
\hline & Red meat fat removed & -0.40646 & \\
\hline \multirow{9}{*}{ "Starch foods" } & Potato & 0.66418 & \multirow{9}{*}{$4.56 \%$} \\
\hline & Breakfast cereals & 0.52251 & \\
\hline & Potato with fat & 0.47055 & \\
\hline & Legumes & 0.45527 & \\
\hline & Full cream & 0.40847 & \\
\hline & Cooked vegetables & 0.36178 & \\
\hline & Cheese sauce & 0.35377 & \\
\hline & Pasta & 0.32992 & \\
\hline & Jam & 0.32221 & \\
\hline \multirow{3}{*}{ "Nuts and rice foods" } & Peanut butter & 0.55276 & \multirow{3}{*}{$3.63 \%$} \\
\hline & Nuts and peanuts & 0.39124 & \\
\hline & Rice mealie rice & 0.34955 & \\
\hline \multirow{3}{*}{ "Vegetable-rich foods" } & Vegetables & 0.61485 & \multirow{3}{*}{$3.13 \%$} \\
\hline & Organ meat & 0.40243 & \\
\hline & Butter & -0.34338 & \\
\hline \multirow{2}{*}{ "Alcoholic drinks" } & Shooters & 0.80795 & \multirow{2}{*}{$2.67 \%$} \\
\hline & Cocktails & 0.79207 & \\
\hline
\end{tabular}

Table 1. Factor loadings of different food items on the eight latent dietary factors identified using factor analysis with Promax rotation. *Factor loadings $\geq 3.0$ or $\leq-3.0$. Food groups are sorted by the size of loading coefficients.

\section{Results}

The proportion of preterm birth in the MACE cohort was 17\%, with $14 \%$ late preterm birth and about $3 \%$ very to moderately preterm births. As for the profile of the mothers, the majority were between 20 and 29 years of age (60.4\%), multigravida (57.1\%), high school graduates (79.4\%), unemployed (81.5\%) and had no personal income (45.3\%). Male babies predominated (52.1\%).

Model fitting and comparison. The Score test indicated that the proportional odds assumption is not reasonable, suggesting that separate parameters are needed across the cumulative logits for at least one predictor $(\mathrm{p}=$ 0.006). Thus, we conducted model comparison among the three ordinal logistic regression models, with likelihood ratio tests. The proportional odds model was rejected in favor of both the non-proportional odds model $(p=0.001)$ and the partial proportional odds model $(\mathrm{p}=0.0001)$, while the partial proportional odds model fits as well as the non-proportional odds model $(\mathrm{p}=0.305)$. The Akaike Information Criterion (AIC) and Bayesian Information Criterion (BIC) values were used to compare the performance of the non-proportional and partial proportional odds models. The partial proportional odds model had the lowest AIC and BIC values, compared to the non-proportional odds model (Table 2). This suggested that the partial proportional odds model outperformed the non-proportional models and could be considered as a viable method for modeling the severity level of preterm birth.

The proportional odds assumption was violated for 'starch foods', 'nuts and rice foods' dietary patterns and maternal income, family size and gravida, among socio-demographic factors. The dietary patterns 'energy foods and snacks', 'spreads and fast foods', 'butter, junk foods, and juices' and 'protein-rich foods', 'vegetable-rich foods', 'alcoholic drinks' and the adjusted socio-demographic variables maternal age, education, employment, and infant gender, all satisfied the proportional odds assumption. 
a)

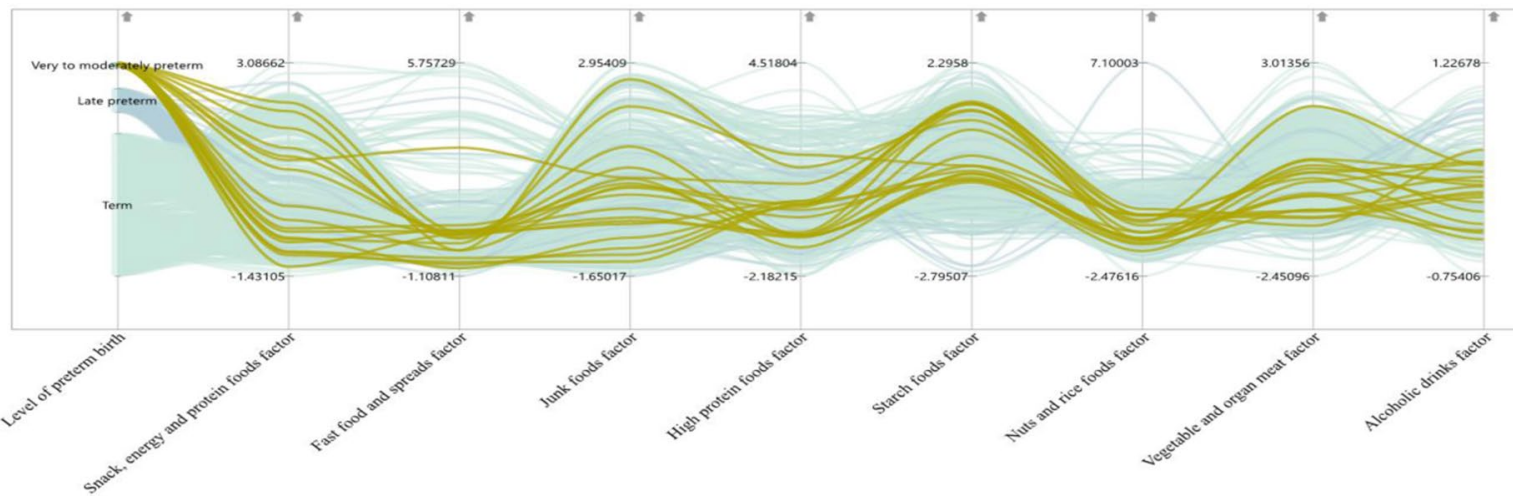

b)

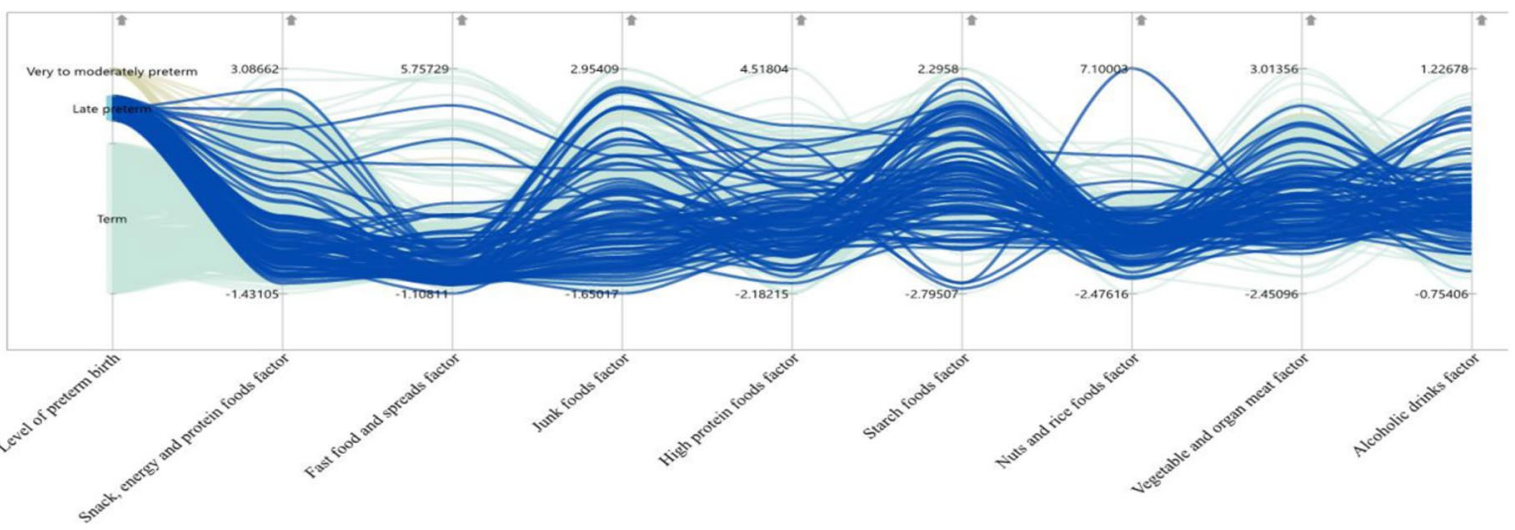

Figure 2. Parallel coordinates plot for trends of latent dietary patterns by levels (a) very/moderately (b) late preterm birth.

\begin{tabular}{|l|l|l|l|}
\hline Test & $\chi^{2}$ & DF & p \\
\hline $\begin{array}{l}\text { Non- proportional odds model vs. } \\
\text { proportional odds model }\end{array}$ & 41.17 & 18 & 0.001 \\
\hline $\begin{array}{l}\text { partial proportional odds model } \\
\text { vs. proportional odds model }\end{array}$ & 27.25 & 6 & 0.0001 \\
\hline $\begin{array}{l}\text { Non-proportional odds model vs. } \\
\text { partial proportional odds model }\end{array}$ & 13.92 & 12 & 0.305 \\
\hline Non- proportional odds model & AIC $=673.93$ & BIC $=844.29$ \\
\hline partial proportional odds model & AIC $=663.85$ & BIC $=780.41$ \\
\hline
\end{tabular}

Table 2. Model comparison values based on likelihood ratio tests, Akaike Information Criterion (AIC) and Bayesian Information Criterion (BIC), for three proportional odds models.

The likelihood ratio chi-square test for the partial proportional odds model was significant with $\chi^{2}(36)=$ $57.42, \mathrm{p}<0.0001$, indicating that the full model with predictors, provided a better fit than the null model, with parameters significantly being non zero (Table 3 ). The partial proportional odds model revealed that the two dietary patterns, 'starch foods' and 'nuts and rice foods', as well as family size, showed a significant differential effect across severity levels of preterm birth. These dietary patterns showed a statistically significant association with highest severity preterm birth, against lower severity levels 1 or 2 of preterm birth outcomes. A mother who consumed 'starch foods' had the greatest risk of having the most severe (level 3) preterm birth category instead of lower severity levels 1 or 2 (Adjusted Odds Ratio $(A O R)=2.09,95 \% \mathrm{CI}=(1.16,3.80), \mathrm{p}=0.014)$. However, the risk of having the most severe preterm birth, as compared to the other categories, decreased by $75 \%$ ( $\mathrm{AOR}=0.25$, $95 \% \mathrm{CI}=(0.099,0.621), \mathrm{p}=0.003)$, for each unit increase in intake of the 'nuts and rice foods' diet (Table 3$)$.

The consumption of 'vegetable-rich foods' and 'alcoholic drinks' latent dietary patterns had a significant effect that did not vary across severity levels of preterm birth. The odds of having higher severity levels 2 and 3 preterm birth compared to level 1 , decreased by $27 \%$ for each unit increase of 'vegetable-rich foods' (AOR $=0.73,(95 \%$ $\mathrm{CI}=(0.531,0.981), \mathrm{p}=0.036)($ Table 3$)$. There was a 3.5 fold $(95 \% \mathrm{CI}=(1.269,9.684), \mathrm{p}=0.015)$ increased risk for preterm birth at a higher severity level, i.e. level 2 or 3 , compared to severity level preterm birth 1 , for one unit increased consumption of alcoholic drinks (Table 3). Furthermore, among the adjusted socio-demographic variables, the risk of having the most severe preterm birth outcome against lower levels was increased for every 


\begin{tabular}{|c|c|c|c|c|c|c|c|c|}
\hline \multirow[b]{2}{*}{ Factors } & \multicolumn{4}{|c|}{ Level 2, Level 3 vs Level 1} & \multicolumn{4}{|c|}{ Level 3 vs level 1, level 2} \\
\hline & $\beta_{1}$ & SE & 95\%CI & AOR & $\beta_{2}$ & SE & 95\%CI & AOR \\
\hline Intercept & $-2.5363^{*}$ & 0.5234 & & & $-7.2263^{*}$ & 1.2210 & & \\
\hline${ }^{\dagger}$ Energy foods and snacks & -0.2272 & 0.1633 & $(0.579,1.097)$ & 0.797 & -0.2272 & 0.1633 & $(0.579,1.097)$ & 0.797 \\
\hline${ }^{\dagger}$ Spreads and fast foods & 0.1736 & 0.1488 & $(0.889,1.592)$ & 1.190 & 0.1736 & 0.1488 & $(0.889,1.592)$ & 1.190 \\
\hline $\begin{array}{l}{ }^{\dagger} \text { Butter, junk foods and } \\
\text { juice }\end{array}$ & -0.0121 & 0.1593 & $(0.723,1.350)$ & 0.988 & -0.0121 & 0.1593 & $(0.723,1.350)$ & 0.988 \\
\hline${ }^{\dagger}$ Protein rich foods & -0.0307 & 0.1458 & $(0.729,1.291)$ & 0.970 & -0.0307 & 0.1458 & $(0.729,1.291)$ & 0.970 \\
\hline Starch foods & -0.1611 & 0.1255 & $(0.666,1.088)$ & 0.851 & $0.7370^{*}$ & 0.3010 & $(1.158,3.769)$ & 2.090 \\
\hline Nuts and rice foods & -0.0217 & 0.1354 & $(0.751,1.276)$ & 0.979 & $-1.3956^{*}$ & 0.4688 & $(0.099,0.621)$ & 0.248 \\
\hline${ }^{\dagger}$ vegetable rich foods & $-0.3148^{*}$ & 0.1619 & $(0.531,0.981)$ & 0.730 & $-0.3148^{*}$ & 0.1619 & $(0.531,0.981)$ & 0.730 \\
\hline${ }^{\dagger}$ Alcoholic drinks & $1.2543^{*}$ & 0.5185 & $(1.269,9.684)$ & 3.505 & $1.2543^{*}$ & 0.5185 & $(1.269,9.684)$ & 3.505 \\
\hline \multicolumn{9}{|c|}{${ }^{\dagger}$ Maternal age (Prime of fertility (20-29 years) ${ }^{\mathrm{a}}$ ) } \\
\hline Teen age ( $15-19$ years) & 0.1676 & 0.3304 & $(0.619,2.259)$ & 1.182 & 0.1676 & 0.3304 & $(0.619,2.259)$ & 1.182 \\
\hline Age of 30 years and above) & $0.5664^{*}$ & 0.2782 & $(1.021,3.039)$ & 1.762 & $0.5664^{*}$ & 0.2782 & $(1.021,3.039)$ & 1.762 \\
\hline \multicolumn{9}{|c|}{${ }^{\dagger}$ Maternal education (College or university ${ }^{\mathrm{a}}$ ) } \\
\hline Primary or less & 0.9499 & 0.6627 & $(0.705,9.476)$ & 2.585 & 0.9499 & 0.6627 & $(0.705,9.476)$ & 2.585 \\
\hline High school & 0.2117 & 0.3303 & $(0.647,2.361)$ & 1.236 & 0.2117 & 0.3303 & $(0.647,2.361)$ & 1.236 \\
\hline \multicolumn{9}{|c|}{${ }^{\dagger}$ Employment (Unemployed ${ }^{a}$ ) } \\
\hline Employed & 0.2574 & 0.3052 & $(0.711,2.353)$ & 1.294 & 0.2574 & 0.3052 & $(0.711,2.353)$ & 1.294 \\
\hline \multicolumn{9}{|c|}{ Maternal annual income (\$2000 and above $\left.{ }^{a}\right)$} \\
\hline No personal income & 0.2106 & 0.3906 & $(0.574,2.654)$ & 1.234 & 0.4944 & 1.1064 & $(0.187,14.339)$ & 1.640 \\
\hline Less than $\$ 2000$ & 0.1745 & 0.3984 & $(0.545,2.600)$ & 1.191 & 1.6579 & 1.0444 & $(0.634,40.644)$ & 5.248 \\
\hline Family size & 0.0573 & 0.0709 & $(0.922,1.217)$ & 1.059 & 0.4055* & 0.1342 & $(1.153,1.951)$ & 1.500 \\
\hline \multicolumn{9}{|l|}{ Gravida (Multigravidaa ${ }^{a}$} \\
\hline Primagravida & -0.0540 & 0.2698 & $(0.558,1.608)$ & 0.947 & 0.1038 & 0.5447 & $(0.381,3.227)$ & 1.109 \\
\hline \multicolumn{9}{|l|}{${ }^{\dagger}$ Infant gender $\left(\right.$ Male $\left.^{\mathrm{a}}\right)$} \\
\hline Female & 0.0715 & 0.2209 & $(0.697,1.656)$ & 1.074 & 0.0715 & 0.2209 & $(0.697,1.656)$ & 1.074 \\
\hline $\begin{array}{l}\text { Score test for proportional } \\
\text { odds assumption }\end{array}$ & \multicolumn{8}{|c|}{$\chi^{2}=36.187 \mathrm{Df}=18 \mathrm{p}$-value $=0.006$} \\
\hline $\begin{array}{l}\text { Goodness of fit } \\
\text { (likelihood ratio) }\end{array}$ & \multicolumn{8}{|c|}{$\chi^{2}=57.4216 \mathrm{Df}=24 \mathrm{p}$-value $<0.0001$} \\
\hline
\end{tabular}

Table 3. Partial proportional odds model for severity levels of preterm birth. *Significant at 0.05 level. ${ }^{a}$ Reference category ${ }^{\dagger}$ proportional odds assumption holds and have the same coefficient values in the two cumulative logits.

one additional person in the family $(\mathrm{AOR}=1.50,95 \% \mathrm{CI}=(1.153,1.951), \mathrm{p}=0.002)$, and being in the age group of 30 years and above $(\mathrm{AOR}=1.76,95 \% \mathrm{CI}=(1.021,3.069), \mathrm{p}=0.041)($ Table 3$)$.

\section{Discussions}

The differential effect of maternal dietary patterns across different severity levels of preterm birth was examined using the partial proportional odds ordinal model. The result showed a significant protective effect of 'vegetable-rich foods', as well as 'nuts and rice foods', for experiencing the most severe preterm birth category. Previous prospective cohort studies ${ }^{42,43}$ found that the Mediterranean-style dietary pattern, characterized by high consumption of fruits and vegetables during pregnancy, was associated with a decrease in the risk of late preterm birth. However, we found that an increase in consumption of a 'vegetable-rich foods' dietary pattern, was related to a decreased risk of preterm birth at both very/moderate and late preterm birth. This may possibly be due to the high loading of vegetables and negative loading of butter, implying that a maternal diet, with frequent consumption of vegetables, could contribute to a lowered odds of preterm birth. This is similar to the finding of a study in Norway, which found evidence that increasing scores for the "prudent" dietary patterns, characterized by diets which are rich in vegetables and fruits, was found to be associated with a lowered risk of preterm birth as a whole ${ }^{23}$.

Our findings are also consistent with the outcomes of a study of dietary pattern and its association with preterm birth in Singapore, that showed a dietary pattern high in vegetables, fruits, and white rice, is associated with a lower risk of preterm birth ${ }^{44}$. Our findings are further consistent with a study in China, which showed that maternal diet with frequent consumption of vegetables, might contribute significantly to lowering odds of experiencing a preterm birth outcome ${ }^{30}$. A study in Singapore found that the consumption of the 'vegetable, fruit and rice' pattern, which includes 'nut and rice foods', was found to be associated with a reduced risk of preterm birth outcome $^{45}$. Likewise, our investigation of the consumption of 'nuts and rice foods' varied between different severity levels of preterm birth and also had evidence of lower risk of having very/moderately preterm birth outcome, as compared to late preterm or term birth outcome.

A Norwegian mother and child cohort study ${ }^{23}$, found that an increase in scores of the "traditional" (potatoes, fish, boiled vegetables) dietary pattern, was associated with a lower risk of preterm birth. However, our study 
showed that women who follow 'starch foods' dietary pattern (characterized by high consumption of potatoes, breakfast cereals, potatoes with fat, legumes, cooked vegetables), is associated with the most severe level of preterm birth. Here, the effect of 'starch foods' dietary pattern, varied across the different severity levels of preterm birth. This is due to the use of the partial proportional odds model, which considered the severity level of preterm birth, on top of other studies that use the multinomial logistic regression model. This may also be attributed to the diets having a high glycemic index, such as potatoes and potatoes fried with fat. These have a high loading on the starch foods dietary pattern by increasing blood glucose levels, similar to the study focusing on pregnant women with diabetes, who deliver preterm babies ${ }^{46,47}$. An increase in consumption of alcoholic drinks was associated with a higher risk of preterm birth, this association being similar across all severity levels of preterm births. Moreover, the study indicated that older age mothers had a significantly higher risk of preterm birth across all severity levels. This is consistent with other studies that showed that the risk of having a preterm baby was higher for older mothers, and further that this risk increased, with an increase in severity level of preterm birth ${ }^{39,48}$.

The strength of this study lies in the use of a more parsimonious method, the partial proportional odds model, that allows the predictors that meet the proportional odds assumption to take the same coefficient for all severity levels of preterm birth, and other predictors to vary across the severity levels of preterm birth, thereby ensuring that there is no potential loss in accuracy of prediction.

Ordinal models assume the proportional odds assumption across severity levels of preterm births, compared to multinomial logit models, which completely ignore the sequential order of preterm births. The assumption of proportional odds model, however, was not supported by the data for all the factors. The partial proportional odds model bridges the gap between the proportional odds and the multinomial logit models ${ }^{41}$. As a result, we used the partial proportional odds model, which accommodates the variables that failed to satisfy the proportional odds model assumption. Unlike previous studies, which were based on the effect of consumption of single food items, a data-driven exploratory factor analysis was used to extract dietary patterns that facilitate understanding of a variety of food consumption habits of the cohort. The limitation of the study is that the data is only adjusted for socio-demographic factors. It is possible that our findings could be biased due to unmeasured confounding variables.

\section{Conclusions}

This study found that the 'vegetable-rich foods' and 'nuts and rice foods' dietary patterns were associated with a reduced likelihood of preterm birth. The dietary patterns such as 'starch foods' and 'alcoholic drinks' and older age were factors that were associated with an increased likelihood of preterm birth. The study further showed 'starch foods' and 'nuts and rice foods' dietary patterns, as well as family size, had a differential effect at different severity levels of preterm birth. The use of partial proportional odds model allowed for modeling the effect of dietary patterns on the severity of preterm birth, allowing for flexibility over the assumption of homogeneity of threshold-specific covariate effects and may consequently allow for a more proper application of models for ordered responses, than is the case for the standard proportional odds methods.

\section{Data availability}

The data that support the findings of this study are available from the MACE study but restrictions apply to the availability of these data, which were used under license for the current study, hence are not publicly available. Data are however available from the authors upon reasonable request and with permission from the MACE study.

Received: 18 March 2019; Accepted: 11 March 2020;

Published online: 26 March 2020

\section{References}

1. World Health Organization (WHO). Born too soon: the global action report on preterm birth (2012).

2. Nour, N. M. Premature delivery and the millennium development goal. Reviews in obstetrics and gynecology 5, 100 (2012).

3. Feng, Y., Abdel-Latif, M. E., Bajuk, B., Lui, K. \& Oei, J. L. Causes of death in infants admitted to Australian neonatal intensive care units between 1995 and 2006. Acta Paediatrica 102, e17-e23 (2013).

4. Petrini, J. R. et al. Increased risk of adverse neurological development for late preterm infants. The Journal of pediatrics 154(169-176), e163 (2009)

5. Blencowe, H. et al. National, regional, and worldwide estimates of preterm birth rates in the year 2010 with time trends since 1990 for selected countries: a systematic analysis and implications. The Lancet 379, 2162-2172 (2012).

6. Baker, P. N. \& Kenny, L. Obstetrics by ten teachers. (CRC Press, 2011).

7. Black, R., Laxminarayan, R., Temmerman, M. \& Walker, N. Community-Based Care to Improve Maternal, Newborn, and Child Health-Reproductive, Maternal, Newborn, and Child Health: Disease Control Priorities, (Volume 2). (2016).

8. Raju, T. N., Higgins, R. D., Stark, A. R. \& Leveno, K. J. J. P. Optimizing care and outcome for late-preterm (near-term) infants: a summary of the workshop sponsored by the National Institute of Child Health and Human Development. 118, 1207-1214 (2006).

9. Roberts, G. et al. Rates of early intervention services in very preterm children with developmental disabilities at age 2 years. $\mathbf{4 4}$, 276-280 (2008)

10. Saigal, S. \& Doyle, L. W. J. T. L. An overview of mortality and sequelae of preterm birth from infancy to adulthood. 371, 261-269 (2008).

11. Donoghue, D., Lincoln, D., Morgan, G., Beard, J. J. A. \& Health, N. Z. j. o. p. Influences on the degree of preterm birth in New South Wales. 37, 562-567 (2013).

12. Shapiro-Mendoza, C. K. \& Lackritz, E. M. Epidemiology of late and moderate preterm birth. In Seminars in Fetal and Neonatal Medicine WB Saunders 17, 120-125 (2012).

13. Tanz, L. J. et al. Preterm Delivery and Maternal Cardiovascular Disease in Young and Middle-Aged Adult WomenClinical Perspective. Circulation 135, 578-589 (2017).

14. Nnam, N. Improving maternal nutrition for better pregnancy outcomes. Proceedings of the Nutrition Society 74, 454-459 (2015).

15. Blumfield, M. L. et al. Dietary balance during pregnancy is associated with fetal adiposity and fat distribution-. The American journal of clinical nutrition 96, 1032-1041 (2012).

16. Abu-Saad, K. \& Fraser, D. Maternal nutrition and birth outcomes. Epidemiologic reviews 32, 5-25 (2010). 
17. Dean, S. V. et al. Born Too Soon: Care before and between pregnancy to prevent preterm births: from evidence to action. Reproductive health 10, S3 (2013).

18. Requejo, J. et al. Born Too Soon: Care during pregnancy and childbirth to reduce preterm deliveries and improve health outcomes of the preterm baby. Reproductive health 10, S4 (2013).

19. Myhre, R. et al. Intakes of Garlic and Dried Fruits Are Associated with Lower Risk of Spontaneous Preterm Delivery, 2. The Journal of nutrition 143, 1100-1108 (2013).

20. Englund-Ögge, L. et al. Association between intake of artificially sweetened and sugar-sweetened beverages and preterm delivery: a large prospective cohort study-. The American journal of clinical nutrition 96, 552-559 (2012).

21. Halldorsson, T. I., Strøm, M., Petersen, S. B. \& Olsen, S. F. Intake of artificially sweetened soft drinks and risk of preterm delivery: a prospective cohort study in 59,334 Danish pregnant women-. The American journal of clinical nutrition 92, 626-633 (2010).

22. Baron, R. et al. The Relationships of Health Behaviour and Psychological Characteristics with Spontaneous Preterm Birth in Nulliparous Women. Maternal and child health journal 21, 873-882 (2017).

23. Englund-Ögge, L. et al. Maternal dietary patterns and preterm delivery: results from large prospective cohort study. Bmj 348, g1446 (2014).

24. Rasmussen, M. A., Maslova, E., Halldorsson, T. I. \& Olsen, S. F. Characterization of dietary patterns in the Danish national birth cohort in relation to preterm birth. PLoS One 9, e93644 (2014).

25. Grieger, J. A., Grzeskowiak, L. E. \& Clifton, V. L. Preconception Dietary Patterns in Human Pregnancies Are Associated with Preterm Delivery-3. The Journal of nutrition 144, 1075-1080 (2014).

26. Bloomfield, F. H. How is maternal nutrition related to preterm birth? Annual review of nutrition 31, 235-261 (2011),

27. Hu, F. B. Dietary pattern analysis: a new direction in nutritional epidemiology. Current opinion in lipidology 13, 3-9 (2002).

28. Cespedes, E. M. \& Hu, F. B. Dietary patterns: from nutritional epidemiologic analysis to national guidelines. 899-900 (Oxford University Press, 2015)

29. Martin, C. L., Sotres-Alvarez, D. \& Siega-Riz, A. M. Maternal Dietary Patterns during the Second Trimester Are Associated with Preterm Birth-3. The Journal of nutrition 145, 1857-1864 (2015).

30. Lu, M.-S. et al. Maternal dietary patterns during pregnancy and preterm delivery: a large prospective cohort study in China. Nutrition journal 17, 71 (2018).

31. Saunders, L. et al. Effect of a M editerranean Diet during Pregnancy on Fetal Growth and Preterm Delivery: Results From a F rench Caribbean Mother-Child Cohort Study (TIMOUN). Paediatric and perinatal epidemiology 28, 235-244 (2014).

32. Walker, S. H. \& Duncan, D. B. Estimation of the probability of an event as a function of several independent variables. Biometrika 54, 167-179 (1967).

33. McCullagh, P. Regression models for ordinal data. Journal of the royal statistical society. Series B (Methodological), 109-142 (1980).

34. Agresti, A. An introduction to categorical data analysis. Report No. 0471226181, (2007).

35. Hosmer, D. W. Jr., Lemeshow, S. \& Sturdivant, R. X. Applied logistic regression. Vol. 398 (John Wiley \& Sons, 2013).

36. Parsons, N. R., Costa, M. L., Achten, J. \& Stallard, N. Repeated measures proportional odds logistic regression analysis of ordinal score data in the statistical software package R. Computational Statistics \& Data Analysis 53, 632-641 (2009).

37. McCullagh, P. \& Nelder, J. A. Generalized linear models. Vol. 37 (CRC press, 1989).

38. Black, R. E. et al. Maternal and child undernutrition and overweight in low-income and middle-income countries. The lancet 382, 427-451 (2013)

39. Donoghue, D., Lincoln, D., Morgan, G. \& Beard, J. Influences on the degree of preterm birth in New South Wales. Australian and New Zealand journal of public health 37, 562-567 (2013).

40. O'Connell, A. A. \& Liu, X. Model diagnostics for proportional and partial proportional odds models. Journal of Modern Applied Statistical Methods 10, 15 (2011).

41. Peterson, B. \& Harrell, F. E. Jr. Partial proportional odds models for ordinal response variables. Applied statistics. 205-217 (1990).

42. Mikkelsen, T. B. et al. Association between a Mediterranean-type diet and risk of preterm birth among Danish women: a prospective cohort study. Acta obstetricia et gynecologica Scandinavica 87, 325-330 (2008).

43. Haugen, M. et al. Mediterranean-type diet and risk of preterm birth among women in the Norwegian Mother and Child Cohort Study (MoBa): a prospective cohort study. Acta obstetricia et gynecologica Scandinavica 87, 319-324 (2008)

44. Palmer, D. J., Metcalfe, J. \& Prescott, S. L. Preventing disease in the 21 st century: the importance of maternal and early infant diet and nutrition. Journal of Allergy and Clinical Immunology 130, 733-734 (2012).

45. Chia, A.-R. et al. A vegetable, fruit, and white rice dietary pattern during pregnancy is associated with a lower risk of preterm birth and larger birth size in a multiethnic Asian cohort: the Growing Up in Singapore Towards healthy Outcomes (GUSTO) cohort study-3. The American journal of clinical nutrition 104, 1416-1423 (2016).

46. Köck, K., Köck, F., Klein, K., Bancher-Todesca, D. \& Helmer, H. Diabetes mellitus and the risk of preterm birth with regard to the risk of spontaneous preterm birth. The Journal of Maternal-Fetal \& Neonatal Medicine 23, 1004-1008 (2010).

47. Thangaratinam, S. et al. Interventions to reduce or prevent obesity in pregnant women: a systematic review. (2012)

48. Newburn-Cook, C. V. \& Onyskiw, J. E. Is Older Maternal Age a Risk Factor for Preterm Birth and Fetal Growth Restriction? A SystematicReview. Health care for women international 26, 852-875 (2005).

\section{Acknowledgements}

We wish to acknowledge the Mother and Child in the Environment cohort study participants, all study fieldworkers, and nursing staff at the participating clinics and hospitals. We also sincerely thank all the international collaborators (Utrecht, Michigan) and local collaborators of the MACE Study. The Mother and Child in the Environment Cohort study is funded by the National Research Foundation (grant number: 90550), Medical Research Council, South Africa, AstraZeneca, South Africa and the Flagship funding from University of KwaZulu-Natal. AA Mitku is grateful to DAAD (German Academic Exchange Program) for the scholarship.

\section{Author contributions}

A.A.M., T.Z. and R.N.N. developed the study design. A.A.M. organized the data, conducted the statistical analysis and drafted the manuscript. All authors critically reviewed and made substantial contributions to the manuscript. All authors read and approved the final manuscript.

\section{Competing interests}

The authors declare no competing interests.

\section{Additional information}

Correspondence and requests for materials should be addressed to A.A.M.

Reprints and permissions information is available at www.nature.com/reprints. 
Publisher's note Springer Nature remains neutral with regard to jurisdictional claims in published maps and institutional affiliations.

(c) (i) Open Access This article is licensed under a Creative Commons Attribution 4.0 International License, which permits use, sharing, adaptation, distribution and reproduction in any medium or format, as long as you give appropriate credit to the original author(s) and the source, provide a link to the Creative Commons license, and indicate if changes were made. The images or other third party material in this article are included in the article's Creative Commons license, unless indicated otherwise in a credit line to the material. If material is not included in the article's Creative Commons license and your intended use is not permitted by statutory regulation or exceeds the permitted use, you will need to obtain permission directly from the copyright holder. To view a copy of this license, visit http://creativecommons.org/licenses/by/4.0/.

(c) The Author(s) 2020 